\title{
Experimental measurement of mass transfer resistances in a membrane based adiabatic microchannel absorber
}

\author{
Mercedes de Vega ${ }^{1}$, Néstor García-Hernando ${ }^{1}$, María Venegas ${ }^{1}$ \\ ${ }^{1}$ Universidad Carlos III de Madrid \\ Avda. Universidad 30, 28911 Leganés, Madrid, Spain \\ mdevega@ing.uc3m.es; ngarcia@ing.uc3m.es; mvenegas@ing.uc3m.es
}

\begin{abstract}
In this paper, measurements of the absorption rate obtained in an adiabatic membrane based microchannel absorber using three different membranes characterized by their pore diameter, thickness and porosity are presented. The mass transfer resistance is mainly due to the resistance in the solution bulk that represents $85 \%$ of the overall mass transfer resistance. The influence of the driving force, that is, the pressure potential is also shown. When the pore size is reduced by $45 \%$, the absorption rate is reduced accordingly. To obtain a similar absorption rate the pressure potential must augment in $1 \mathrm{kPa}$ to compensate for this reduction in pore size. Thickness of the membrane has a similar influence, confirming previous simulated results.
\end{abstract}

Keywords: Nanoporous membrane, Microchannel, Adiabatic absorption, Water-lithium bromide.

\section{Introduction}

The absorber is one of the most performance limiting and volume demanding components in absorption chillers. In these devices, a high mass transfer rate can be achieved by getting as much interfacial area as possible between the refrigerant vapour and the solution. A possibility is the use of membrane contactors in microchannel mass exchangers. A thorough review of this technology can be found in [1]. While a high number of numerical or analytical models exists in the literature, fewer experimental studies can be found. $\mathrm{In}_{2} \mathrm{O}-\mathrm{LiBr}$ applications, the absorption rate in a plate adiabatic absorber was measured for different membranes and a model was developed to analyse the effect of porosity, pore diameter and thickness, among other properties of the membranes in $[2,3]$. In that case, the solution film thickness was $4 \mathrm{~mm}$. This thickness was afterwards considered too large to obtain convenient absorption rates [4, 5]. A cooled absorber using a superhydrophobic nanofibrous membrane with nominal pore size of 1 micron and $80 \%$ porosity was tested in [6,7]. An absorption rate of about $0.006 \mathrm{~kg} / \mathrm{m}^{2} \mathrm{~s}$, using channels of 100 micron thickness and a flow velocity of $5 \mathrm{~mm} / \mathrm{s}$ was obtained. Adiabatic absorption was modelled and compared with cooled absorption in [8] using microchannels in the absorber. In the present work, measurements in an adiabatic absorber using porous fibers for the heat and mass transfer between the solution and the vapor phase is considered. The performance of the microchannel absorber is evaluated for three different membranes working with the $\mathrm{H}_{2} \mathrm{O}-\mathrm{LiBr}$ solution-refrigerant pair.

\section{Experimental set-up}

The configuration considered for the absorber in the present study is shown in Fig.1. It is a plate-and-frame membrane module consisting of a vapor channel, the contact membrane and the solution microchannels. The microchannels are mechanized in a stainless steel plate, and are $150 \mu \mathrm{m}$ height and $1.5 \mathrm{~mm}$ width. A picture of the stainless steel plate and the microchannels is shown in Fig. 1. The characteristics of the three compared membranes are summarized in Table1.

A photograph of the experimental bench where the adiabatic absorber is tested is shown in Fig.2. Two Coriolis type flowmeters (CFMS010M - Micromotion ${ }^{\mathrm{TM}}$ ), measure the mass flow rate and the density of the solution at the inlet and outlet of the absorber. The range of measurement for the mass flow rate is $0.002-110 \mathrm{~kg} / \mathrm{h}$ with an uncertaintity of $\pm 0.1 \%$. The range for the measured density is 0 to $5000 \mathrm{~kg} / \mathrm{m}^{3}$ with an uncertainty of $\pm 0.5 \mathrm{~kg} / \mathrm{m}^{3}$. Temperature is measured by PT100 thermoresistances (OMEGA series PR-17). The corresponding calculated uncertainty is $\pm(0.15+0.002 * \mathrm{~T}){ }^{\circ} \mathrm{C}$. Pressure is measured with absolute pressure transducers (OMEGA PX409-005AI-EH) in a range of 0-5psi, with an uncertainty of \pm $0.05 \%$ f.s. 


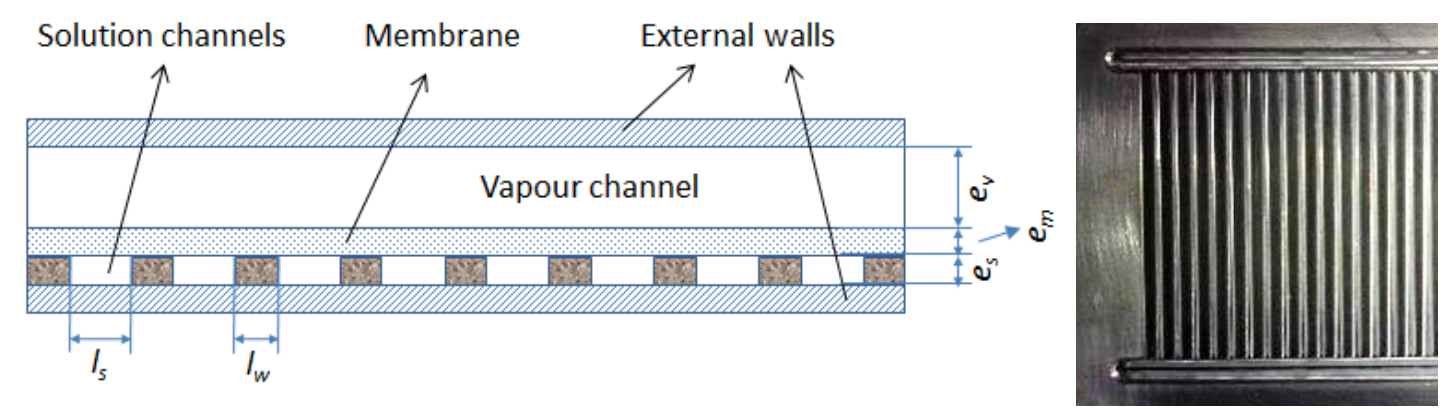

Fig. 1: Cross-sectional scheme of the adiabatic absorber and picture of the microchannels.

Table 1: Characteristics of the compared membranes (data from $[9,10,11])$.

\begin{tabular}{|l|l|l|l|}
\hline Parameter & FALP29325 & PTU0453001 & PTFE0453005 \\
\hline Supporting layer & Yes & No & Yes \\
\hline Thickness, em $(\mu \mathrm{m})$ & 175 & $25-51$ & $76-127$ \\
\hline Porosity $(\%)$ & 85 & $\sim 90$ & $\sim 90$ \\
\hline Pore diameter, dp $(\mu \mathrm{m})$ & 1 & 0.45 & 0.45 \\
\hline
\end{tabular}

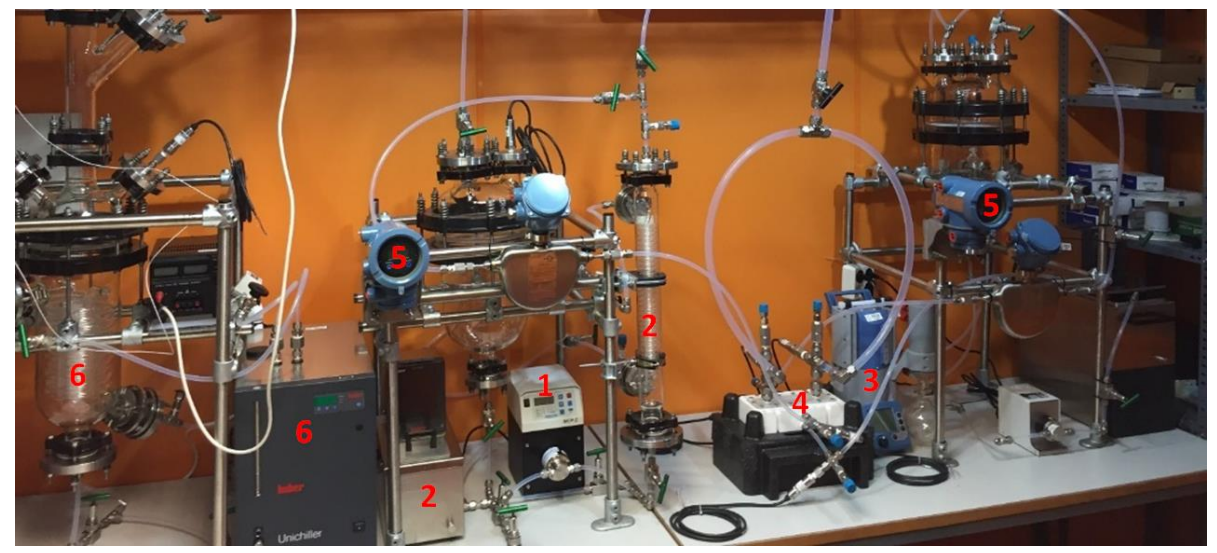

Fig. 2: 1-solution pump, 2-thermostatic system for temperature regulation, 3-vacuum pump, 4-absorber, 5-Coriolis flowmeters, 6vapour generation system.

\section{Experimental results}

We are interested in comparing the mass transfer resistances corresponding to the different membranes and operating conditions. The overall mass transfer resistance is equal to:

$$
R_{O V}=R m+R s=\frac{P_{v}-P_{s}}{J}
$$

$P v$ is the measured pressure in the vapour channel, while $P s$ in Eq. (1) is the partial pressure of the water vapour, calculated at the inlet measured solution temperature $(T s)$ and concentration $(x)$. In the following, the difference $P v-P S$ will be defined as the pressure potential, as it is the driving force of the process. The overall mass transfer resistance between water vapour and solution $\left(R_{O V}\right)$ in Eq. (1), includes the resistance to diffusion through the solution boundary layer $(R s)$ and the resistance to diffusion of water vapour through the membrane $(R m)$. 
The absorption rate across the membrane into the $\mathrm{LiBr}$ solution, $J$, depends on the measured mass flow rate of vapour absorbed and the mass transfer area $(A)$ :

$$
J=\dot{m}_{v a} /_{A}
$$

In Eq. (2), the mass vapour absorbed $m_{V A}$ is obtained from the Coriolis flow meters. Results of the absorption rate, given a solution mass flow rate, are shown in Fig. 3 with, in bars, the standard deviation for each case. The higher the driving pressure potential, the higher absorption rate is obtained. Comparing the two membranes with equal pore diameter, when the thickness almost double, the pressure potential must also double to obtain a similar absorption rate. When comparing the effect of reducing the diameter pore from 1 micron to 0.45 micron, the absorption rate, for a given pressure potential is less than halved. This agrees with previous model results $[2,12]$.

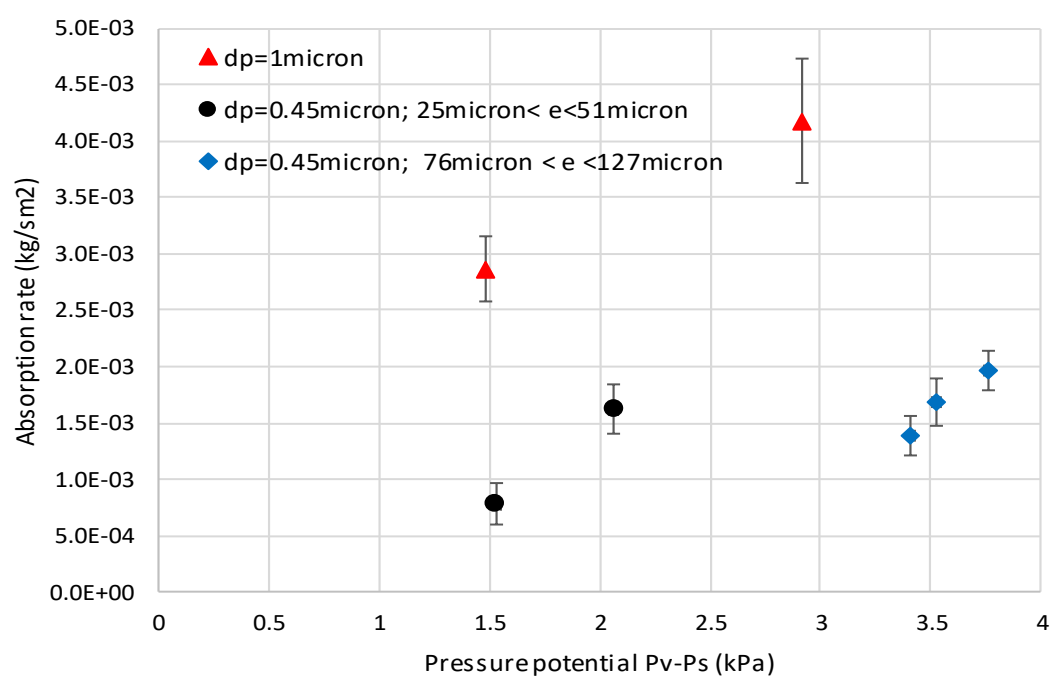

Fig. 3: Absorption rate.

For the experimental conditions used in the present work, the membrane is working in the transition flow regime. In this case, applying the thermal resistance analogy, the membrane mass transfer resistance $R m$ can be obtained as in [12]. According to this, $R m$ is inversely proportional to the pore diameter squared and linearly proportional to the membrane thickness. The results show the following values: the higher membrane mass transfer resistance is, as expected, for the membrane with the lower pore diameter and higher thickness and it is equal to $295 \mathrm{kPam}^{2} \mathrm{~s} / \mathrm{kg}$. For the same pore diameter, but lower thickness the membrane resistance decreases to $118 \mathrm{kPam}^{2} \mathrm{~s} / \mathrm{kg}$, which is the lower value. The $1 \mu \mathrm{m}$ pore diameter membrane presents a resistance of $217.8 \mathrm{kPam}^{2} \mathrm{~s} / \mathrm{kg}$. In the present case, for the combination of pore diameter and thickness, it results that the membrane resistance is lower for the $0.45 \mu \mathrm{m}$ and low thickness. This agrees with the predictions of [2,12]. For the given membrane characteristics, the importance of the two terms in Eq. (1) is represented in Fig.4. It is seen that, for the membrane characteristics of our experiments, the bulk solution is the limiting resistance, being an $85 \%$ of the overall mass transfer resistance. This was not case in the experiments of [1,2], as the solution thickness in this case was much higher.

\section{Conclusion}

The higher thickness and low diameter pore oblige to work with higher pressure driving potentials to obtain a reasonable vapour mass flow rate absorbed. For the combination of flow regime and diameter pore, thickness and porosity in our experiments, the dominant resistance to mass transfer occurs in the solution boundary layer. Low pore diameter and high thickness increase this effect. 


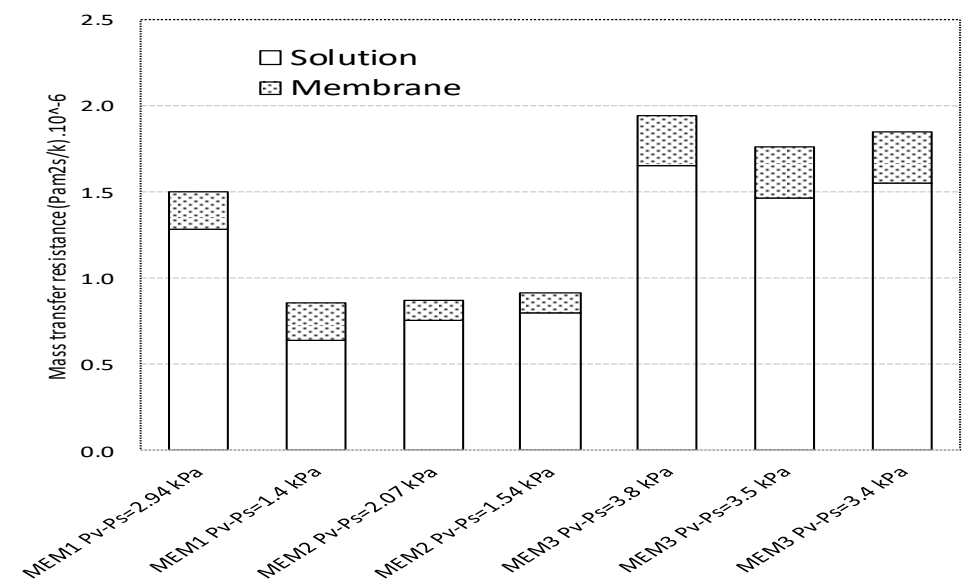

Fig. 4: Mass transfer resistances (membrane and solution) for each experimental case.

\section{Acknowledgements}

The financial support of this study by the Ministerio de Economía, Industria y Competitividad of Spain through the research grant DPI2017-83123-R is greatly appreciated.

\section{References}

[1] F. Asfand and M. Bourouis, "A review of membrane contactors applied in absorption refrigeration systems," Renew Sustain Energy Rev., vol. 45, pp. 173-191, 2015.

[2] A. H. H. Ali and P. Schwerdt, "Characteristics of the membrane utilized in a compact absorber for lithium bromidewater absorption chillers," Int. J. Refrig., vol. 32, pp. 1886-1896, 2009.

[3] A. H. H. Ali, "Design of a compact absorber with a hydrophobic membrane contactor at the liquid-vapor interface for lithium bromide-water absorption chillers," Appl. Energy, vol. 87, pp. 1112-1121, 2010.

[4] D. Yu, J. Chung, S. Moghaddam, "Parametric study of water vapour absorption into a constrained thin film of lithium bromide solution," Int. J. Heat Mass Transf., vol. 55, pp. 5687-5695, 2012.

[5] F. Asfand, Y. Stiriba, M. Bourouis, "Impact of the solution channel thickness while investigating the effect of membrane characteristics and operating conditions on the performance of water-LiBr membrane-based absorbers," Appl. Therm. Eng., vol. 108, pp. 866-877, 2016.

[6] R. N. Isfahani, S. Moghaddam, "Absorption characteristics of lithium bromide ( $\mathrm{LiBr}$ ) solution constrained by superhydrophobic nanofibrous structures," Int. J. Heat Mass Transf., vol. 63, pp. 82-90, 2013.

[7] R. N. Isfahani, K. Sampath, S. Moghaddam, "Nanofibrous membrane-based absorption refrigeration system," Int. J. Ref., vol. 36, pp. 2297-2307, 2013.

[8] M. Venegas, M. de Vega, N. García-Hernando, "Adiabatic vs non-adiabatic membrane-based rectangular microabsorbers for H2O-LiBr absorption chillers," Energy, vol. 134, pp. 757-766, 2017.

[9] http://www.merckmillipore.com/ES/es/product/Fluoropore-Membrane-PTFE-hydrophobic-1.0m-293mm-whiteplain,MM_NF-FALP29325 Last accessed 7 september 2018

[10] https://www.sterlitech.com/ptfe-unlaminated-membrane-filter-ptu0453001.html Last accessed 7 september 2018

[11] https://www.sterlitech.com/ptfe-laminated-membrane-filter-ptfe0453005.html Last accessed 7 september 2018

[12] M. Venegas, M. de Vega, N. García-Hernando, U. Ruiz-Rivas, "A simple model to predict the performance of H2OLiBr absorber operating with a microporous membrane,” Energy, vol. 96, pp. 383-393, 2016. 